CZASOPISMO INŻYNIERII LĄDOWEJ, ŚRODOWISKA I ARCHITEKTURY JOURNAL OF CIVIL ENGINEERING, ENVIRONMENT AND ARCHITECTURE

JCEEA, t. XXXIII, z. 63 (1/I/16), styczeń-marzec 2016, s. 53-60

Krzysztof PAWLOWSKI ${ }^{1}$

Sebastian WALCZAK ${ }^{2}$

\title{
ANALIZA PARAMETRÓW FIZYKALNYCH W OCENIE JAKOŚCI CIEPLNEJ ELEMENTÓW BUDYNKÓW NISKOENERGETYCZNYCH
}

\begin{abstract}
Realizacja obowiązujących wymagań technicznych w zakresie ochrony cieplnej $\mathrm{z}$ uwzględnieniem standardu niskoenergetycznego, polega na sprawdzeniu wielu parametrów całego budynku, ale także jego przegród zewnętrznych i ich złączy. Ich określanie wg obowiązujących przepisów prawnych i norm przedmiotowych budzi wiele wątpliwości i niejasności w zakresie procedur obliczeniowych i interpretacji zagadnień fizykalnych. Celem pracy jest analiza w zakresie wpływu uwzględnienia przepływów ciepła w polu (2D) - mostków cieplnych, przy ocenie izolacyjności cieplnej przegród zewnętrznych i ich złączy.

Dla przykładowego budynku określono parametry fizykalne przegród zewnętrznych i ich złączy: współczynnik przenikania ciepła $\mathrm{U}\left[\mathrm{W} /\left(\mathrm{m}^{2} \cdot \mathrm{K}\right)\right]$ dla przegród zewnętrznych, liniowy współczynnik przenikania ciepła $\Psi[\mathrm{W} /(\mathrm{m} \cdot \mathrm{K})]$ dla mostków cieplnych przy zastosowaniu programu komputerowego TRISCO, rozkład temperatur $w$ analizowanych złączach budowlanych oraz na podstawie temperatury minimalnej na wewnętrznej powierzchni przegrody $\theta_{\text {si,min. }}\left[{ }^{\circ} \mathrm{C}\right]-$ czynnik temperaturowy $f_{\mathrm{Rsi}}[-]$.

Na podstawie przedstawionych obliczeń i analiz zaproponowano wprowadzenie pewnych zmian w zapisach istniejących w ,Warunkach Technicznych” oraz kompleksowej metody w zakresie oceny jakości cieplnej elementów obudowy budynków niskoenergetycznych. Dążenie do spełnienia standardu budownictwa niskoenergetycznego powinno opierać się na jasnych, precyzyjnych zasadach wynikających z podstawowych zasad szeroko rozumianej „fizyki budowali” z zastosowaniem nowoczesnych narzędzi numerycznych. Obudowa budynku (przegrody zewnętrzne i ich złącza) powinna stanowić podstawowy aspekt w zakresie oceny jakości cieplnej i energetycznej całego budynku.
\end{abstract}

Słowa kluczowe: budynek niskoenergetyczny, jakość cieplna, parametry fizykalne

\footnotetext{
${ }^{1}$ Autor do korespondencji/corresponding author: Krzysztof Pawłowski, Uniwersytet TechnologicznoPrzyrodniczy im. J. i J. Śniadeckich w Bydgoszczy, Wydział Budownictwa, Architektury i Inżynierii Środowiska, al. Prof. S. Kaliskiego 7, 85-796 Bydgoszcz, 600-612-705, krzypaw@utp.edu.pl

${ }^{2}$ Sebastian Walczak, Uniwersytet Technologiczno-Przyrodniczy im. J. i J. Śniadeckich w Bydgoszczy
} 


\section{Wybrane zagadnienia fizykalne w zakresie oceny jakości cieplnej elementów budynków niskoenergetycznych}

W Krajowym planie wsparcia [1] sformułowano rekomendowaną do stosowania w praktyce krajową definicję budynku niskoenergetycznego: „budynek o niskim zużyciu energii”" to budynek, spełniający wymogi związane z oszczędnością energii i izolacyjnością zawarte w przepisach techniczno-użytkowych, o których mowa w art. 7 ust. 1 pkt 1 ustawy - Prawo budowlane [2], tj. w szczególności dział X oraz załącznik 2 do [3] obowiązujące od 1.01.2021 roku (w przypadku budynków zajmowanych przez władze publiczne oraz będących ich własnością - od 1.01.2019 r.). Zgodnie z [1] i w myśl [3] za energooszczędne można uznać budynki, które charakteryzują się powierzchniowym wskaźnikiem sezonowego zapotrzebowania na ciepło $\mathbf{E P}_{\mathbf{H}+\mathbf{W}}$ poniżej $\mathbf{7 0} \mathrm{kWh} /\left(\mathrm{m}^{2} \cdot\right.$ rok $)$ dla budynku jednorodzinnego oraz poniżej $65 \mathrm{kWh} /\left(\mathrm{m}^{2} \cdot\right.$ rok $)$ - dla budynku wielorodzinnego. Jednoczenie spełnienie kryterium cieplnego polega na utrzymaniu wysokiej termoizolacyjności wszystkich przegród otaczających ogrzewane wnętrze: $\mathrm{U}_{\mathrm{c}}(\mathrm{U}) \leq \mathrm{U}_{\mathrm{c}(\max )}\left(\mathrm{U}_{(\max )}\right)$, gdzie $\mathrm{U}_{\mathrm{c}}, \mathrm{U}, \mathrm{U}_{\mathrm{c}(\max )}, \mathrm{U}_{(\max )}$ - oznaczają odpowiednio: współczynnik przenikania ciepła określonej przegrody w budynku oraz jego dopuszczalną wartość maksymalną, ustaloną dla pewnej grupy przegród (ściany, stropodachy, posadzki na gruncie, okna, itp.

Zagadnienia fizyki cieplnej budowli sprowadzają się przede wszystkim do analizy cieplnej przegród zewnętrznych budynków, poddanych oddziaływaniom, zmiennych w czasie, temperatur zewnętrznych i wewnętrznych. W wielu przypadkach rozwiązanie przepływu ciepła sprowadza się do określenia przenikania ciepła przez płaską przegrodę budowlaną w polu jednowymiarowym (1D), bez uwzględnienia przepływu ciepła w polu dwuwymiarowym (2D) i trójwymiarowym (3D). Jednak realnym (rzeczywistym) polem wymiany ciepła jest zazwyczaj przegroda zewnętrzna jako fragment budynku, a więc połączona systemem złączy z przegrodami przylegającymi (stropem, ścianą zewnętrzną lub wewnętrzną lub podłogą na gruncie). Jeżeli powstałe płaskie lub przestrzenne pole temperatur $\mathrm{w}$ istotny sposób zmienia ukształtowany w polu jednowymiarowym prostoliniowy przebieg izoterm i adiabat - zakrzywiając je, wówczas można mówić o mostku cieplnym w przegrodzie lub złączu [4].

Należy podkreślić, że obecnie obliczane wartości współczynnika przenikania ciepła $U_{c}$ oraz wartości graniczne $U_{c(\max )}, U_{(\max )}$ wg rozporządzenia [3], dla pojedynczej przegrody, nie uwzględniają dodatkowych strat ciepła wynikających z występowania mostków cieplnych. Ich udział uwzględnia się przy wyznaczaniu współczynnika strat ciepła przez przenikanie $\mathrm{H}_{\mathrm{Tr}}$.

Jakość cieplna elementów budynków jest określana także w postaci czynnika temperaturowego złączy w przegrodach budynku dla potwierdzenia wymagania: $f_{\text {Rsi }} \geq f_{\text {Rsi(kryt). }}$ Sprawdzenia wymagają wszystkie złącza (w zależności od ich rodzaju), obliczeniem w układzie dwu- lub trójwymiarowym i stanowią o istocie realizacji warunku niedopuszczenia do kondensacji powierzchniowej pary wod- 
nej na przegrodach osłaniających budynek. Określenie czynnika temperaturowego $f_{\mathrm{Rsi}} \mathrm{W}$ analizowanym złączu przegród zewnętrznych wymaga określenia temperatury minimalnej na wewnętrznej powierzchni przegrody oraz w miejscu mostka cieplnego, przy założeniu odpowiednich temperatur powietrza wewnętrznego $\left(\theta_{\mathrm{i}}\right)$ i zewnętrznego $\left(\theta_{\mathrm{e}}\right)$ i dla mostków cieplnych zastosowania przestrzennego modelu przegrody wg PN-EN ISO 10211:2008 [5]. Natomiast wymaganą wartość granicznego czynnika temperaturowego $f_{\text {Rsi(kryt) }}$ ustala się w funkcji temperatury $\mathrm{t}_{\mathrm{i}}$ oraz wilgotności względnej powietrza $\varphi_{\mathrm{i}}[\%]$, pomieszczenia, którego dotyczy. Wymienione parametry (temperatura wewnętrzna oraz wilgotność powietrza wpomieszczeniu) przesądzają o wartości czynnika temperaturowego $f_{\text {Rsi(kryt), de- }}$ cydującej granicy w ocenie poprawności rozwiązań konstrukcyjnych złącza. Wg normy PN-EN ISO 13788:2003 [6], czynnik temperaturowy $f_{\text {Rsi(kryt) }}$ oblicza się lub przyjmuje $\mathrm{w}$ zależności od zastosowanego w budynku rodzaju wentylacji (wentylacja grawitacyjna - dominująca $\mathrm{w}$ budownictwie mieszkaniowym lub wentylacja mechanicznej, będąca często składnikiem systemów klimatyzacyjnych, pozwalających w prawie dowolny sposób kształtować właściwości mikroklimatu wnętrz). W rozporządzeniu [1], mimo uznania normy PN-EN ISO 13788 [6] za obowiązującą w projektowaniu, istnieje odstępstwo od jej wymagań, polegające na przyjęciu średniej miesięcznej wilgotności względnej powietrza wewnętrznego w stałej wartości $\varphi_{\mathrm{i}}=0,50(50 \%)$ (punkt 2.2.2 Załącznika nr 2 [1]) dla pomieszczeń z temperaturą wewnętrzną równą co najmniej $20^{\circ} \mathrm{C}$. Równocześnie dopuszczono (bez obliczeń) dla tych pomieszczeń przyjmowanie wartości czynnika $f_{\text {Rsi(kryt) }}=0,72$ co praktycznie oznacza rezygnację z ustalania klas wilgotności pomieszczeń zaopatrzonych w wentylację grawitacyjną.

Na podstawie przeprowadzonych analiz zaproponowano kompleksowy algorytm (schemat) określania parametrów fizykalnych w ocenie jakości cieplnej elementów budynku niskoenergetycznego (rysunek 1).

\section{Obliczenia wybranych parametrów fizykalnych przegród zewnętrznych i złączy budynku}

Kompleksowa ocena jakości cieplnej elementów budynków niskoenergetycznych obejmuje analizę szeregu parametrów fizykalnych.

W ramach pracy na wstępie określono parametry fizykalne wybranych złączy budowlanych ściany zewnętrznej trójwarstwowej ( $\mathrm{z}$ ociepleniem w postaci płyty z pianki PIR gr. $12 \mathrm{~cm}$ o $\lambda=0,022 \mathrm{~W} /(\mathrm{m} \cdot \mathrm{K})$, płyty z pianki PUR gr. $12 \mathrm{~cm}$ o $\lambda=0,035 \mathrm{~W} /(\mathrm{m} \cdot \mathrm{K}))$, płyty styropianowej $\mathrm{gr} .12 \mathrm{~cm}$ o $\lambda=0,040 \mathrm{~W} /(\mathrm{m} \cdot \mathrm{K})$, przy zastosowaniu programu komputerowego TRISCO, zgodnie z zasadami opisanymi w PN-EN ISO 10211:2008 [5]. Wyniki obliczeń zestawiono w tabeli 1.

Wykonanie szczegółowych obliczeń, przy zastosowaniu programu komputerowego, pozwala na uzyskanie miarodajnych wyników parametrów fizykalnych. Ich wartości zależą od zastosowanego materiału budowlanego (konstrukcyjnego) 


\section{OCENA JAKOŚCI CIEPLNEJ ELEMENTÓW BUDYNKÓW NISKOENERGETYCZNYCH}

I. Określenie wartości współczynnika przenikania ciepła $\mathbf{U} / \mathbf{U}_{\mathbf{c}}\left(\mathbf{U}_{1 \mathrm{D}}\right)\left[\mathrm{W} /\left(\mathrm{m}^{2} \cdot \mathrm{K}\right)\right]$ dla zewnętrznych przegród budowlanych: ściana zewnętrzna, stropodach, stolarka okienna, podłoga na gruncie wg obowiązujących metod obliczeniowych

II. Określenie wartości liniowego współczynnika przenikania ciepła $\Psi[\mathrm{W} /(\mathrm{m} \cdot \mathrm{K})]$ dla złączy budowlanych (mostków cieplnych) przy zastosowaniu programu komputerowego lub na podstawie profesjonalnych katalogów mostków cieplnych

\begin{tabular}{|l|l|l|}
\hline III. Określenie strat ciepła przez przenikanie & III. Określenie strat ciepła przez przenikanie
\end{tabular} przez przegrodę zewnętrzną:

$\mathbf{H}_{\mathbf{D}}=\mathrm{U}_{\mathrm{c}} \cdot \mathrm{A}_{\mathrm{i}}+\sum \Psi_{\mathrm{i}} \cdot 1_{\mathrm{i}}[\mathrm{W} / \mathrm{K}] /$

$\mathbf{H}_{\mathrm{g}}=\mathrm{A} \cdot \mathrm{U}+\mathrm{P} \cdot\left(\Psi+\Psi_{\mathrm{g}, \mathrm{e}}\right)[\mathrm{W} / \mathrm{K}]$ przez obudowę budynku (przegrody zewnętrzne):

$\mathbf{H}=\mathbf{H}_{\mathrm{D}}+\mathbf{H}_{\mathrm{g}}[\mathrm{W} / \mathrm{K}]$

IV. Określenie współczynnika przenikania ciepła z uwzględnieniem mostków cieplnych: $\mathbf{U}_{\mathbf{k}}\left(\mathbf{U}_{2 \mathrm{D}}\right)$

\begin{tabular}{l|l}
$=\mathbf{H}_{\mathbf{D}} / \mathbf{A}\left[\mathrm{W} /\left(\mathrm{m}^{2} \cdot \mathrm{K}\right)\right]$ & ków cieplnych: $\mathbf{U}_{\text {sr. }}\left(\mathbf{U}_{2 \mathbf{D}}\right)=\mathbf{H} / \mathbf{A}\left[\mathrm{W} /\left(\mathrm{m}^{2} \cdot \mathrm{K}\right)\right]$ \\
\hline V. Określenie czynnika temperaturowego $f_{\text {Rsi }}[-]$ na podstawie temperatury minimalnej na wewnętrznej
\end{tabular} IV. Określenie średniego współczynnika przenikania ciepła $\mathrm{z}$ uwzględnieniem mostpowierzchni przegrody przy zastosowaniu programu komputerowego lub na podstawie katalogu mostków cieplnych

Rys. 1. Algorytm oceny jakości cieplnej elementów budynków niskoenergetycznych

Fig. 1. Algorithm for thermal quality evaluation of low-energy building elements

Tabela 1. Wyniki obliczeń parametrów fizykalnych złączy budowlanych - opracowanie własne na podstawie [8]

Table 1. Calculation results of building joint physical parameters - own research based on [8]

\begin{tabular}{|c|c|c|c|c|c|c|}
\hline \multicolumn{7}{|c|}{ Parametry fizykalne przegród zewnętrznych i ich złączy } \\
\hline wariant & $\mathrm{I}$ & II & III & $\mathrm{I}$ & II & III \\
\hline $\begin{array}{c}\mathbf{U}_{\mathrm{c}} \\
{\left[\mathrm{W} /\left(\mathrm{m}^{2} \cdot \mathrm{K}\right)\right]}\end{array}$ & 0,134 & 0,184 & 0,199 & \multirow{2}{*}{\multicolumn{3}{|c|}{$\mathbf{t}_{\min .}\left[{ }^{\circ} \mathrm{C}\right] / f_{\mathrm{Rsi}}[-]$}} \\
\hline Złącze & \multicolumn{3}{|c|}{$\Psi_{\mathbf{i}}[\mathrm{W} /(\mathrm{m} \cdot \mathrm{K})$} & & & \\
\hline Z 1 & 0,057 & 0,070 & 0,074 & $16,48 / 0,912$ & $15,43 / 0,886$ & $15,12 / 0,875$ \\
\hline $\mathrm{Z} 2$ & 0,035 & 0,048 & 0,051 & $18,46 / 0,961$ & $17,90 / 0,948$ & $17,73 / 0,943$ \\
\hline Z3 & 0,043 & 0,059 & 0,065 & $18,37 / 0,959$ & $17,69 / 0,942$ & $17,47 / 0,937$ \\
\hline $\mathrm{Z} 4$ & 0,039 & 0,056 & 0,063 & $17,37 / 0,934$ & $16,80 / 0,920$ & $16,60 / 0,915$ \\
\hline Z 5 & 0,017 & 0,022 & 0,024 & $13,64 / 0,841$ & $13,08 / 0,827$ & $12,84 / 0,821$ \\
\hline Z 6 & 0,032 & 0,034 & 0,035 & $16,01 / 0,900$ & $15,43 / 0,886$ & $15,24 / 0,881$ \\
\hline $\mathrm{Z} 7$ & 0,137 & 0,159 & 0,168 & $15,89 / 0,897$ & $14,78 / 0,869$ & $14,41 / 0,860$ \\
\hline $\mathrm{Z} 8$ & 0,071 & 0,087 & 0,095 & $17,91 / 0,948$ & $17,32 / 0,933$ & $17,12 / 0,928$ \\
\hline Z9 & 0,265 & 0,327 & 0,349 & $14,34 / 0,858$ & $13,99 / 0,850$ & $13,87 / 0,847$ \\
\hline \multicolumn{7}{|c|}{$\begin{array}{l}\text { Z1 - Połączenie ścian zewnętrznych w narożniku, Z2 - Połączenie ściany zewnętrznej z wewnętrzną, Z3 - } \\
\text { Połączenie ściany zewnętrznej ze stropem w przekroju przez wieniec, Z4 - Połączenie ściany zewnętrznej } \\
\text { z oknem w przekroju przez nadproże, Z5 - Połączenie ściany zewnętrznej z oknem w przekroju przez } \\
\text { podokiennik, Z6 - Połączenie ściany zewnętrznej z oknem w przekroju przez ościeżnicę, Z7 - Połączenie } \\
\text { ściany zewnętrznej ze stropodachem, Z8 - Połączenie ściany zewnętrznej z płytą balkonową (przy } \\
\text { zastosowaniu łącznika izotermicznego), Z9 - Połączenie ściany zewnętrznej z podłogą na gruncie }\end{array}$} \\
\hline
\end{tabular}


go), rodzaju i grubości izolacji cieplnej oraz ukształtowania struktury materiałowej analizowanego złącza. Posługiwanie się wartościami przybliżonymi i orientacyjnymi, np. w oparciu o PN-EN ISO 14683:2008 [7], staje się nieuzasadnione, ponieważ nie uwzględniają zmiany układów materiałowych oraz rodzaju i grubości izolacji cieplnej.

Uwzględnienie realnie występujących w przegrodach dwu- i trójwymiarowych przepływów ciepła może prowadzić do znaczących różnic wartości parametrów cieplnych $(\mathrm{U}, \mathrm{H})$, charakteryzujących przegrody tego samego budynku. Przegrody (np. ściany zewnętrzne) z dużą powierzchnią otworów okiennych lub z niektórymi, trudnymi w ograniczeniu mostkami cieplnymi (balkony, nadproża, narożniki), mogą posiadać wysokie wartości współczynnika U i stwarzać zagrożenie kondensacji wilgoci na wewnętrznej powierzchni przegród.

W drugim etapie obliczeń określono straty ciepła przez ścianę parteru budynku (z oknem różnej wielkości) z uwzględnieniem liniowych mostków cieplnych. Do obliczeń zastosowano wartości $\Psi_{\mathrm{i}}[\mathrm{W} /(\mathrm{m} \cdot \mathrm{K})$, określone w pierwszym etapie obliczeń - tabela 1 . Wyniki parametrów cieplnych określonych wg kompleksowego algorytmu (rysunek 1) zestawiono w tabeli 2.

W trzecim etapie obliczeń określono parametry cieplne dla całego budynku jednorodzinnego z uwzględnieniem strat ciepła przez pojedyncze przegrody i przepływu ciepła w polu 2D (w postaci liniowych mostków cieplnych). Wyniki obliczeń zestawiono w tabeli 3.

Udział mostków cieplnych w całkowitych stratach ciepła przez zewnętrzne przegrody zewnętrzne jest znaczący. Metodyka ich uwzględniania wg rozporządzenia [9] jest dyskusyjna, jej stosowanie może skutkować znaczną rozbieżnością wyników obliczeń w odniesieniu do danego budynku, w zależności od podejścia projektanta (certyfikatora).

Tabela 2. Wyniki obliczeń parametrów cieplnych ścian zewnętrznych budynku - opracowanie własne Table 2. Calculation results of physical parameters of building external walls - own research

\begin{tabular}{|l|c|c|c|c|c|c|}
\hline Analizowane parametry ścian & \multicolumn{3}{|c|}{ ściana I } & \multicolumn{3}{c|}{ ściana II } \\
\hline $\begin{array}{l}\text { współczynnik przenikania ciepła ściany } \\
\text { zewnętrznej } \mathrm{U}_{\mathrm{c}}\left(\mathrm{U}_{1 \mathrm{D}}\right)\end{array}$ & 0,134 & 0,184 & 0,199 & 0,134 & 0,184 & 0,199 \\
\hline $\begin{array}{l}\text { straty ciepła wynikające z występowania } \\
\text { liniowych mostków cieplnych: } \sum \Psi_{\mathrm{i}} \cdot 1 \mathrm{li} \\
{[\mathrm{W} / \mathrm{K}]}\end{array}$ & 1,30 & 1,41 & 1,47 & 1,13 & 1,19 & 1,23 \\
\hline $\begin{array}{l}\text { całkowite straty ciepła przez ścianę ze- } \\
\text { wnętrzną: } \mathrm{H}_{\mathrm{DI}}=\mathrm{U}_{\mathrm{c}} \cdot \mathrm{A}_{\mathrm{i}}+\sum \Psi_{\mathrm{i}} \cdot \mathrm{li}[\mathrm{W} / \mathrm{K}]\end{array}$ & 2,60 & 3,19 & 3,40 & 3,35 & 4,24 & 4,53 \\
\hline $\begin{array}{l}\text { pole powierzchni ściany zewnętrznej } \\
\text { z uwzględnieniem złączy budowlanych: } \\
\mathrm{A}_{\text {oil }}\end{array}$ & \multicolumn{5}{|c|}{14,65} & \multicolumn{5}{|c|}{21,55} \\
\hline $\begin{array}{l}\text { współczynnik przenikania ciepła ściany } \\
\text { zewnętrznej z uwzględnieniem linio- } \\
\text { wych mostków cieplnych: } \mathrm{U}_{2 \mathrm{D}}=\mathrm{H}_{\mathrm{D} 1} / \mathrm{A}_{\mathrm{oil}}\end{array}$ & 0,18 & 0,22 & 0,23 & 0,16 & 0,20 & 0,21 \\
\hline
\end{tabular}


Tabela 3. Wyniki obliczeń parametrów cieplnych przegród zewnętrznych budynku - opracowanie własne

Table 3. Calculation results of thermal parameters of external building partitions - own research

\begin{tabular}{|c|c|c|c|}
\hline Parametry cieplne elementów budynku & wariant I & wariant II & wariant III \\
\hline $\begin{array}{l}\left.\quad \mathbf{U}_{1 \mathrm{D}}{ }^{*}\right)\left[\mathrm{W} /\left(\mathrm{m}^{2} \cdot \mathrm{K}\right)\right] \\
\text { - ściany zewnętrznej: } \\
\text { - przegrody przeźroczystej: } \\
\text { - stropodachu: } \\
\text { - podłogi na gruncie: }\end{array}$ & $\begin{array}{c}0,134 \\
0,90 \\
0,102 \\
0,13 \\
\end{array}$ & $\begin{array}{c}0,184 \\
0,90 \\
0,165 \\
0,20 \\
\end{array}$ & $\begin{array}{c}0,199 \\
0,90 \\
0,187 \\
0,21 \\
\end{array}$ \\
\hline 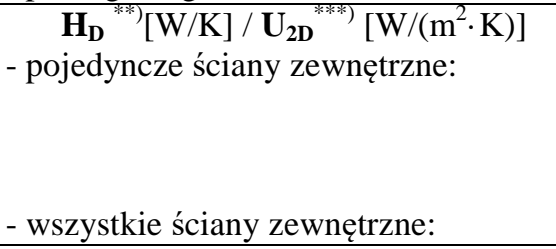 & $\begin{array}{l}10,34 / 0,22 \\
15,90 / 0,33 \\
11,00 / 0,22 \\
8,81 / 0,17 \\
\mathbf{4 6 , 0 5} / 0,23\end{array}$ & $\begin{array}{l}12,22 / 0,26 \\
17,52 / 0,37 \\
12,74 / 0,25 \\
10,89 / 0,22 \\
\mathbf{5 3 , 3 7} / 0,27\end{array}$ & $\begin{array}{l}12,84 / 0,27 \\
18,05 / 0,38 \\
13,37 / 0,27 \\
11,56 / 0,23 \\
\mathbf{5 5 , 8 2} / 0,28\end{array}$ \\
\hline - stropodach: & $\mathbf{9 , 4 5} / 0,12$ & $\mathbf{1 3 , 8 0} / 0,18$ & $\mathbf{1 5 , 3 3} / 0,20$ \\
\hline - podłoga na gruncie: & $\mathbf{1 6 , 7 9} / 0,22$ & $\mathbf{2 4 , 2 1} / 0,32$ & $\mathbf{2 6 , 2 0} / 0,34$ \\
\hline - cała obudowa budynku: & $\mathbf{7 2 , 2 9} / 0,21$ & $\mathbf{9 1 , 3 8} / 0,26$ & $\mathbf{9 7 , 3 5} / 0,28$ \\
\hline \multicolumn{4}{|c|}{$\begin{array}{l}\left.{ }^{*}\right) \mathbf{U}_{1 \mathrm{D}}-\text { wartość współczynnika przenikania ciepła przegród zewnętrznych w polu jednowymiarowym } \\
{\left[\mathrm{W} /\left(\mathrm{m}^{2} \cdot \mathrm{K}\right)\right]} \\
{ }^{* * *)} \mathbf{H}_{\mathbf{D}}-\text { współczynnik strat ciepła przez przenikanie z uwzględnieniem liniowych mostków cieplnych } \\
{\left[{ }^{* * *)} / \mathrm{K}\right]} \\
\mathbf{U}_{2 \mathrm{D}}-\text { wartość współczynnika przenikania ciepła przegród zewnętrznych z uwzględnieniem przepływu } \\
\text { ciepła w polu dwuwymiarowym }\left[\mathrm{W} /\left(\mathrm{m}^{2} \cdot \mathrm{K}\right)\right]\end{array}$} \\
\hline
\end{tabular}

\section{Podsumowanie i wnioski}

Ocena jakości cieplnej elementów budynku niskoenergetycznego powinna obejmować kompleksową analizę parametrów fizykalnych przegród zewnętrznych z uwzględnieniem wpływu mostków cieplnych (rysunek 1).

Przedstawione powyżej oraz w pracach $[4,10]$ przykłady obliczeniowe potwierdzają potrzebę prowadzenia dokładnych obliczeń przy zastosowaniu programów komputerowych z uwzględnieniem parametrów powietrza wewnętrznego i zewnętrznego. Obniżanie wartości granicznych współczynników przenikania ciepła $\mathbf{U}_{\max }$ bez uwzględniania przepływów ciepła w polu (2D) i (3D) czyli mostków cieplnych, powoduje rzeczywiste dopuszczenie większych strat ciepła przez przegrody budowlane i ich złącza. Ponadto zasadne staje się określenie wartości granicznych liniowego współczynnika przenikania ciepła $\Psi_{\max }$ na poziomie $0,10 \div 0,20 \mathrm{~W} /(\mathrm{m} \cdot \mathrm{K})$ w zależności od specyfiki analizowanego złącza, podobnie jak wg wytycznych NFOŚiGW [11] w zakresie projektowania budynków w standardzie NF15 i NF40. Sformułowanie wartości granicznych wskaźnika zapotrzebowania na energię użytkową EU ograniczy także negatywny wpływ strat w miejscu występowania mostków cieplnych. 
Analizując złącza ścian zewnętrznych (tabela 1) można stwierdzić, że nie występuje ryzyko kondensacji powierzchniowej pary wodnej, ponieważ obliczone wartości czynników temperaturowych $f_{\mathrm{Rsi}}[-]$ są większe od wartości granicznej czynnika temperaturowego $f_{\text {Rsi, (kryt.) }}$ [-]. Wartość graniczna (krytyczna) czynnika temperaturowego, przy uwzględnieniu parametrów powietrza wewnętrznego i zewnętrznego, analizowanych wariantów obliczeniowych wynosi $f_{\text {Rsi, (kryt.) }}=0,778$.

\section{Literatura}

[1] Uchwała Rady Ministrów z dnia 22 czerwca 2015 r. w sprawie przyjęcia „Krajowego planu mającego na celu zwiększenie liczby budynków o niskim zużyciu energii”.

[2] Ustawa z dnia 7 lipca 1994 r. - Prawo budowlane (DzU z 2013 r. poz. 1409, z późn. $\mathrm{zm}$.).

[3] Rozporządzenie Ministra Transportu, Budownictwa i Gospodarki Morskiej zmieniające rozporządzenie w sprawie warunków technicznych, jakim powinny odpowiadać budynki i ich usytuowania (DzU z 2013 r., poz. 926).

[4] Dylla A., Praktyczna fizyka cieplna budowli. Szkoła projektowania złączy budowlanych. Wydawnictwo Uczelniane UTP w Bydgoszczy, Bydgoszcz 2009.

[5] PN-EN ISO 10211:2008 Mostki cieplne w budynkach. Strumienie ciepła i temperatury powierzchni. Obliczenia szczegółowe.

[6] PN-EN ISO 13788: 2003 Cieplno-wilgotnościowe właściwości komponentów budowlanych i elementów budynku. Temperatura powierzchni wewnętrznej umożliwiająca uniknięcie krytycznej wilgotności powierzchni wewnętrznej kondensacji. Metody obliczania.

[7] PN-EN ISO 14683:2008 Mostki cieplne w budynkach. Liniowy współczynnik przenikania ciepła. Metody uproszczone i wartości orientacyjne.

[8] Walczak S., Analiza numeryczna złączy ścian zewnętrznych trójwarstwowych w świetle nowych wymagań cieplnych, Praca magisterska napisana pod kierunkiem dr. inż. Krzysztofa Pawłowskiego. Uniwersytet Technologiczno-Przyrodniczy w Bydgoszcz, Bydgoszcz 2015.

[9] Rozporządzenie Ministra Infrastruktury i Rozwoju w sprawie metodologii obliczania charakterystyki energetycznej budynku i lokalu mieszkalnego lub części budynku stanowiącej samodzielną całość techniczno-użytkową oraz sposobu sporządzania i wzorów świadectw charakterystyki energetycznej. (Dz.U. z 2015 r., poz. 376).

[10] Pawłowski K., Projektowanie przegród zewnętrznych w świetle aktualnych warunków technicznych dotyczących budynków. Obliczenia cieplno-wilgotnościowe przegród zewnętrznych i ich złączy, Wydawnictwo Grupa Medium, Warszawa 2016.

[11] Wymagania określające podstawowe wymogi niezbędne do osiągnięcia oczekiwanych standardów energetycznych dla budynków mieszkalnych oraz sposób weryfikacji projektów i sprawdzania wykonywanych domów energooszczędnych, www.nfosigw.gov.pl. 


\section{THE ANALYSIS OF PHYSICAL PARAMETERS IN THE QUALITY ASSESSMENT OF THERMAL ELEMENTS LOW-ENERGY BUILDINGS}

\section{S u m m a r y}

Fulfillment of obligatory technical requirements for thermal protection within the lowenergy standard consists in checking a number of parameters of the entire building, but also its external walls and their joints. Their definition according to the legal regulations and subject standards raises many doubts and ambiguities about calculation procedures and interpretations of physical issues. The basic goal of this work is the analysis of heat flow influence in the area of thermal bridges (2D) with evaluation of thermal insulation of external walls and their joints.

For some building physical parameters external walls and joints were determined: heattransfer coefficient $U[\mathrm{~W} /(\mathrm{m} 2 \cdot \mathrm{K})]$ for external walls, linear heat-transfer coefficient $\Psi[\mathrm{W} /(\mathrm{m} \cdot \mathrm{K})]$ of thermal bridges using a TRISCO software, temperature distribution in the analyzed joints of construction and on the basis on a minimum temperature on the internal surface of the wall $\theta_{\text {si, min }}\left[{ }^{\circ} \mathrm{C}\right]$ (temperature factor $\left.f_{\text {Rsi }}[-]\right)$.

On the basis of calculations and analyses it has been proposed changes to the existing notation in the "Specifications" and complex method in the evaluation of the thermal quality of lowenergy buildings insulation. The aspiration to fulfillment the low-energy buildings standards should be based on clear, precise rules and should be determined on the basic principles of the broadly defined "Construction Physics" with use of modern numerical tools. Building insulation (external walls and their joints) should be an essential aspect in the assessment of the heat and energy quality of the whole building.

Keywords: low-energy building, thermal quality, physical parameters

Przestano do redakcji: 07.06.2016 $r$.

Przyjęto do druku: 30.06.2016 r.

DOI: $10.7862 / \mathrm{rb} .2016 .6$ 